\title{
Experimental Investigation on Flow Characteristics in a Turbine Rotor-Stator Cavity with Inlet at Low Radius
}

\author{
H. L. Ren ${ }^{1 \dagger}$, J. C. Zhang ${ }^{1}$, H. C. Cheng ${ }^{1}$, J. S. Chai ${ }^{2}$ and S. Fu ${ }^{3}$ \\ ${ }^{1}$ Research Center of Simulation Technology, Aero Engine Academy of China, Beijing, 101304, China \\ 2 AECC Shenyang Engine Institute, Shenyang, 110015, China \\ ${ }^{3}$ School of Power and Energy, Northwestern Polytechnical University, Xi' an, 710072, China
}

†Corresponding Author Email: renhl_2012@,163.com

(Received January 22, 2021; accepted August 6, 2021)

\begin{abstract}
An experimental investigation has been designed and performed to determine the fluid flow characteristics in a rotor-stator cavity with large gap ratio and inlet at low radius. In this investigation, the particle image velocimetry (PIV) technique is employed for the velocity measurements of airflow in the rotor-stator cavity. Local swirl ratios are calculated from these velocity distributions. A range of parameter combinations of interest in fluid flow characteristics is covered, including combinations of variations in axial location, rotational Reynolds number (denoted as $\mathrm{Re}_{\varphi}$ ), and inlet nondimensional mass flow rate (denoted as $\mathrm{C}_{\mathrm{W}}$ ). The results indicate that the flow in the rotor-stator cavity is still dominated by circumferential motion. The velocity is basically unchanged along the circumference. However, the velocity increases with the increase of radial position. In different axial positions, the velocity distribution is different. The closer to the rotor, the more uneven the flow in the rotor-stator cavity is. The disturbance of the rotor rotating motion to the fluid mainly occurs in the high radius region, which should be paid more attention to in the process of reforming the flow field characteristics. To the circumferential velocity of low radius fluid, the $\operatorname{Re}_{\varphi}$ is in direct proportion, while the $\mathrm{C}_{\mathrm{W}}$ is in inverse. The swirl ratio in the core region is very close to that in the high radius near the wall region of the rotor, which can be inferred to be caused by the backflow in the rotor-stator cavity.
\end{abstract}

Keywords: Rotor-stator cavity; Rotational Reynolds number; Nondimensional mass flow rate; Swirl ratio; Particle image velocimetry.

\section{NOMENCLATURE}

\begin{tabular}{|c|c|c|c|}
\hline$b$ & outer radius of rotor & $R$ & universal gas constant \\
\hline$C_{W}$ & nondimensional mass flow rate & $r$ & local radial height \\
\hline$D_{n}$ & diameter of the nozzle & $r_{n}$ & radial position of the nozzle \\
\hline$G$ & gap ratio & $r_{\text {in }}$ & inner radius of the rotor-stator cavity \\
\hline$L_{n}$ & axial length of the nozzle & rout & outer radius of the rotor-stator cavity \\
\hline$L_{1}$ & axial position of the sheet light & $S$ & axial spacing \\
\hline$L_{2}$ & axial position of the sheet light & $T^{*}$ & total temperature of the air \\
\hline$L_{1}^{*}$ & $\begin{array}{l}\text { nondimensional axial position of the sheet } \\
\text { light }\end{array}$ & $V$ & $\begin{array}{l}\text { velocity of airflow in the rotor-stator } \\
\text { cavity }\end{array}$ \\
\hline$L_{2}{ }^{*}$ & $\begin{array}{l}\text { nondimensional axial position of the sheet } \\
\text { light }\end{array}$ & $V^{*}$ & nondimensional velocity \\
\hline$m$ & inlet mass flow rate & $\lambda t$ & turbulence parameter \\
\hline$P$ & static pressure of the air & $\rho$ & density \\
\hline$P I V$ & particle image velocimetry & $\omega$ & rotational speed of the rotor \\
\hline $\operatorname{Re}$ & rotational Reynolds number & $\mu$ & dynamic viscosity of the air \\
\hline R1 & inner radius & $\beta$ & swirl ratio \\
\hline
\end{tabular}




\section{INTRODUCTION}

Rotor-stator system is an important part of gas turbine air system, which is composed of rotor and stator. Cooler air bled from the compressor must be supplied to the rotor-stator cavities to cool some high temperature components. Inside the rotor-stator cavity, the flow is divided into three forms, which are axial, radial and circumferential flow respectively. The rotational motion of the rotor induces three forces, which are centrifugal force, Coriolis force and inertial force respectively. Due to the combined action of the flow and forces, the flow characteristics inside the rotor-stator cavities are extremely complex, which has a direct impact on the cooling of components, flange seal and axial force calculation. Therefore, it is very important to obtain the flow field parameters accurately for the stable operation of the engine.

There are many kinds of rotor-stator systems. According to whether there is a shroud, it can be divided into open rotor-stator system (Soo and Princeton 1958; Vaughan 1987; Dorfman 1961; Daily et al.1964) and closed rotor-stator system. For the closed rotor-stator system, it can be divided into several types according to the inlet and outlet modes. Figure 1 shows three common rotor-stator structures with shroud. (a) inlet at center of stator (b) inlet at center of rotor (c) inlet at high radius of stator.

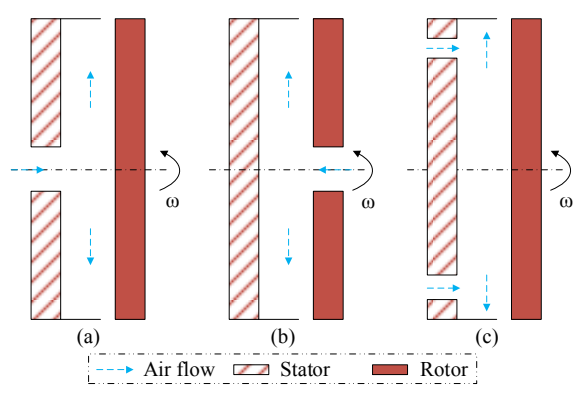

Fig. 1. Rotor-stator system structures.

The most-used structure in the engine is similar to Fig.1(a), which has also been widely studied by many scholars. Owen and Phadke (1980) studied the flow field visualization of the structure in the paper of Bayley and Owen (1970), and obtained the influence of the shroud on the flow field in the rotorstator cavity. Phadke and Owen (1983), Chew (1991), Chew et al. (1992), and Khilnani et al. (1994) have made theoretical and experimental studies on the flow in the rotor-stator system with shroud. Campbell (1978) studied the influence of external flow field and rotation on the sealing characteristics of central inlet stator with shroud. The results show that the flow rate and pressure of external flow field have a great influence on sealing performance, while the rotation has little influence. Similar conclusions are also found in Kobayashi et al. (1984) and Daniels et al. (1992). Hamabe and Ishida (1992), Dadkhah et al. (1992) and Ishida and Hamabe (1997) used different test methods to study the influence of external flow on sealing characteristics. Reichert and Lieser (1999) used the method of theoretical analysis to study the sealing problem of rotor-stator system model. Wu et al. (2007) carried out numerical simulation on the rotor-stator system with vertical inlet at high radius, and found that the flow in the rotor-stator cavity can be divided into two regions.

For the rotor-stator system structure of Fig.1(a), there are three important parameters that affect the flow characteristics in the cavity, which are denoted as G, $\operatorname{Re}_{\varphi}$ and $C_{W} . G$ is the ratio of spacing between the rotor and stator to rotor radius which is called as gap ratio, $R_{\varphi}$ is rotational Reynolds number and $C_{W}$ is the inlet nondimensional mass flow rate. With different $G$ and $\operatorname{Re}_{\varphi}$, the regimes of flow in a rotorstator cavity is different.

In the 1950s, Batchelor and Stewartson respectively studied the internal flow structure of simple rotorstator system. Batchelor (1951) first proposed a flow structure with rotating core in rotor-stator cavity. The flow in the rotor-stator cavity was divided into the rotating disk boundary layer, the stationary disk boundary layer, and the core region between the two boundary layers. In the core region, the fluid rotates at a constant speed below the rotating speed of the rotor, similar to a rigid body. The influence of viscosity on the fluid in the core region can be ignored, while the fluid flowing out of the rotor due to the pump effect is supplemented by the gas in the core region and the boundary layer of the stator. However, Stewartson (1953) proposed another noncore flow structure. In the rotor-stator cavity, the fluid in the boundary layer of the rotor will rotate under the drive of the rotor, and the fluid in the boundary layer of the stator will remain static due to the viscous effect. In the middle of the two boundary layers, the tangential velocity decreases from the velocity near the rotor to zero near the stationary disk. There is no core rotating at a constant speed, which is similar to the flow structure of the free disk.

Since Batchelor and Stewartson proposed their own flow structures in rotor-stator cavity, these two structures have been studied by many scholars (Chew and Vaughan 1988; Childs 2011; Cheah et al. 1994) and have been controversial. Picha and Eckert (1958) studied the effect of shroud on the flow structure in rotor-stator cavity with experimental method. The results show that the tangential velocity of the fluid in the open rotor-stator system is very small, and the rotating core can hardly be identified. Therefore, the Stewartson type flow is obtained. However, the rotating core mentioned by Batchelor can be obtained in the rotor-stator cavity when there is a shroud, and the tangential velocity of the fluid in the core area will decrease with the increase of the clearance between the rotor and the stator. All the above-mentioned research objects are rotor-stator structures without superimposed flow path, which are not affected by external airflow, and become the basic structure of rotor-stator system research (Nece and Daily 1960; Morse 1991; Dijkstra and Heijst 1983; Daily and Nece 1960; Schouveiler et al. 2001). Roy et al. (2001) divided the rotor-stator cavity into two flow regions, the source region and the core region. In the source region, the axial inlet flow is 
critical for the flow, while in the core region, rotation is critical for the flow. Poncet, Schiestel and Chauve (2005), Poncet Chauve and Schiestel (2005) and Poncet and Schiestel (2007) studied the internal flow structure of rotor-stator cavity with or without through flow respectively. The results show that the flow pattern is generally Batchelor type flow in a rotor-stator cavity without axial flow, while there is a transition between Batchelor type flow and Stewartson type flow in a rotor-stator cavity with axial flow, which is consistent with Owen (1989). Meanwhile, Poncet, Chauve and Schiestel (2005) also found that the rotational Reynolds number and axial flow have different effects on the flow structure transition. Increasing the rotational Reynolds number can slow down the transition from Batchelor flow to Stewartson flow, while increasing the axial flow will promote the transition.

The above researches were mainly conducted in the range of parameters: $1000<\mathrm{Re}_{\varphi}<1 \times 10^{6}, 0<\mathrm{G}<0.1$. However, with the increase of engine performance requirements, the $\operatorname{Re}_{\varphi}$ and $G$ are also increasing, which have exceeded the above range. The flow characteristics in rotor-stator cavity need to be further studied.

With the development of computational fluid dynamics (CFD) technology, many researches use simulation method to obtain the flow field in rotorstator cavity, however, the flow results need to be verified by the experimental results. Then, the researches using experimental method to obtain the flow field characteristics in rotor-stator cavity are relatively less. In the research of Coren et al. (2009), LDA technology was used to test the flow field. Turbulence parameters are selected as the main factors to measure the flow structure in the rotorstator cavity. At $\lambda t>0.2$, the axial flow is critical for the flow in the rotor-stator cavity. The tangential velocity in the rotor-stator cavity decreased rapidly with the increase of the distance from the rotor, and the maximum swirl ratio of the fluid in the rotorstator cavity was about 0.1 . At $\lambda t<0.2$, the rotation is critical for the flow. The swirl ratio reaches the maximum value of 0.25 when the dimensionless radius $\mathrm{R} / \mathrm{b}=0.82$. Tao et al. (2007) also used PIV method to study the flow field of rotor-stator cavity with vertical inlet at high radius, which proved that PIV particle imaging technology can be applied to flow field measurement of rotor-stator cavity structure.

It appears from the previous studies that the flow characteristics in rotor-stator cavity have been studied by abundant researchers. However, the flow field in rotor-stator cavity with large gap ratio $(\mathrm{G}=1.7)$ and large rotational Reynolds number $\left(1.1 \times 10^{6}<\operatorname{Re}_{\varphi}<2.4 \times 10^{6}\right)$ still needs to be improved. The flow field in rotor-stator cavity with cooling air inlet at low radius has been far from complete. There is also a lack of available experimental data concerning the flow characteristics. The comparison of the flow field between the near wall region and the core region has not yet been studied experimentally. As such, based on the real engine component size, the present work establishes the rotor-stator cavity test model. The effects of the parameters, such as nondimensional mass flow rate, $\mathrm{C}_{\mathrm{W}}$ and rotational Reynolds number, $\mathrm{Re}_{\varphi}$ on the flow in the rotor-stator system will be evaluated in more detail. The flow field distribution and parameter variation of rotorstator cavity at different axial positions will be obtained using PIV technique.

\section{Experimental apparatus and methods}

\subsection{Experimental apparatus}

The experimental rig is shown in Fig. 2. The air flow required for the test was provided by a compressor. It was divided into two channels after entering a high-pressure air tank which was used to stabilize the air pressure. The primary flow entered the test section through the air inlet valve and the flowmeter. The secondary flow which was utilized to form the particle flow was led out from the air tank, flowed through the flowmeter and entered the particle generator. The particle flow carrying tracer particles mixed with the primary flow and then entered the test section. The exhaust air was collected by the outlet case and emitted to the atmosphere.

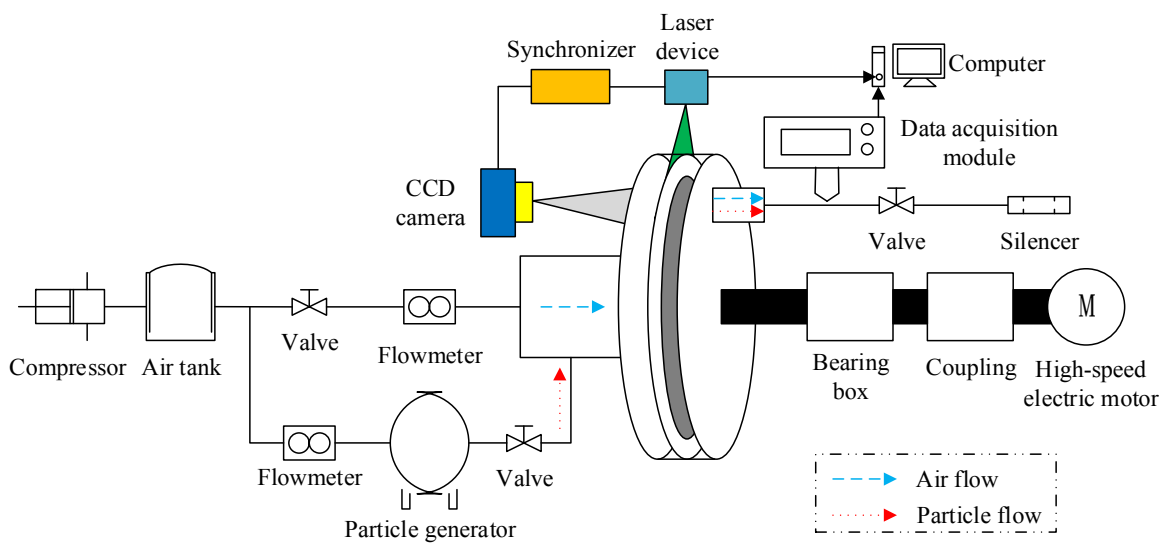

Fig. 2. Schematic diagram of the experimental rig. 
Due to the fact that the air velocity in the rotor-stator cavity is not very high, the conventional metal particles are not suitable for this experiment. Therefore, the moxa smoke was selected as the tracer particles. The diameter of particle produced by the moxa velvet was about $2 \sim 5 \mu \mathrm{m}$, which had good following performance at the experimental speed.

The particle was not easy to adhere to the surface of the rotor, so it had little pollution to the shooting background.

The light source for the PIV measurement was produced by a laser device. The maximum operating frequency was $15 \mathrm{~Hz}$, the laser wavelength was $532 \mathrm{~nm}$ and the thickness of the sheet was about $1 \mathrm{~mm}$. A CCD camera with a resolution of $2048 \times$ 2048 was used for image acquisition in the measurement area, and the lens focal length was 50 $\mathrm{mm}$. In the shooting process, $532 \mathrm{~nm}$ wavelength filter would be added in front of the lens to eliminate the interference caused by other light sources. The synchronizer was used to ensure that the CCD camera and laser device would work at the same time. In the experiment, the flowmeters $(1.5 \% \mathrm{R}$ accuracy) were used for flow measurement. The pressure scanning valves were used for pressure measurement, and the measurement accuracy is \pm $0.05 \%$. The temperatures of the air were measured by K-type thermocouple probes, with accuracy of $\pm 1^{\circ} \mathrm{C}$. The analog signals were converted into digital ones by the data acquisition module and then recorded in the computer. The rotor was driven by a high-speed electric motor. The rotating speed of the rotor was measured by the laser tachometer, with accuracy of $\pm 0.04 \%$.

\subsection{Test section}

Figure 3 shows schematically the layout of the test section. As shown in Fig.3, the stator and the intermediate case are connected by flange, which forms the part of the static structure of the rotorstator system. The rotor is connected to the shaft which is driven by a high-speed motor. The intake cavity is used for mixing the air flow and the particle flow. The mixed air flowed into the rotor-stator cavity from the 60 nozzles in the stator, driven by the rotor and "thrown out" radially. After the mixed air passed through the gap between the intermediate case and the rotor, the annular cavity gathered the mixed air from 20 outlet holes on the outlet case and exhausted the mixed air to the atmosphere through the four outlets. The outlet case is a static structure and cannot contact with the shaft. In order to prevent the air leakage, a magnetic oil seal was used.

Both the window for taking pictures on the stator and the window for transmitting light were made of plexiglass and the inner surfaces were kept flat with the original surfaces, which reduced the influence on the flow field. The window for transmitting light installed on the intermediate case is arc-shaped, with a center angle of $30^{\circ}$ and a width of $45 \mathrm{~mm}$.

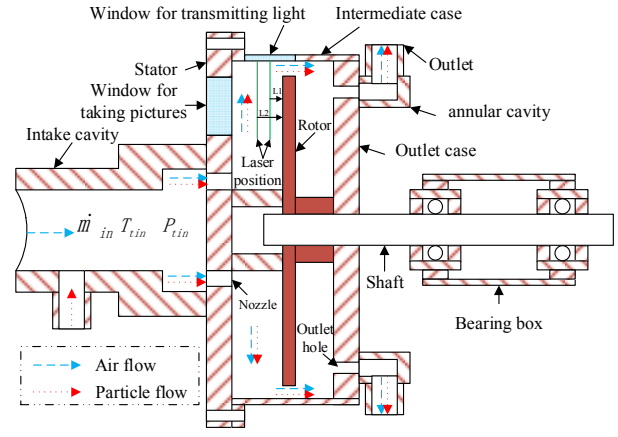

Fig. 3. Schematic of the test section.

In the experiment, two laser positions were selected for measurement. The sheet light entered the rotorstator cavity parallel to the rotor surface. The tracer particles on the plane of the sheet light reflected the sheet light and recorded the information on the camera. In order to reduce the influence of the rotor reflection on the particle light intensity, the surface of the rotor was sprayed with black paint.

The geometric parameters of the experimental section are shown in Table 1 . The outer radius of the rotor-stator cavity $\left(\mathrm{r}_{\text {out }}\right)$ is $0.28 \mathrm{~m}$, the axial spacing $(\mathrm{S})$ is $0.045 \mathrm{~m}$, and the inner radius $\left(\mathrm{r}_{\mathrm{in}}\right.$ ) of the cavity is $0.112 \mathrm{~m}$. The radial position of the nozzle $\left(\mathrm{r}_{\mathrm{n}}\right)$ is $0.117 \mathrm{~m}$. The diameter of the nozzle $\left(\mathrm{D}_{\mathrm{n}}\right)$ is $4 \mathrm{~mm}$. The axial length of the nozzle $\left(\mathrm{L}_{\mathrm{n}}\right)$ is $0.016 \mathrm{~m}$. The center line of the nozzle is perpendicular to the surface of the stator and evenly distributed along the circumference. The axial position of the sheet light is $11 \mathrm{~mm}(\mathrm{~L} 1)$ and $16 \mathrm{~mm}$ (L2) in front of the rotor respectively.

Table 1 Test section geometries

\begin{tabular}{|c|c|c|c|}
\hline Variables & $\mathrm{r}_{\text {out }} / \mathrm{m}$ & $\mathrm{S} / \mathrm{m}$ & $\mathrm{r}_{\text {in }} / \mathrm{m}$ \\
\hline Value & 0.28 & 0.045 & 0.112 \\
\hline Variables & $\mathrm{r}_{\mathrm{n}} / \mathrm{m}$ & $\mathrm{D}_{\mathrm{n}} / \mathrm{m}$ & $\mathrm{L}_{\mathrm{n}} / \mathrm{m}$ \\
\hline Value & 0.117 & 0.004 & 0.016 \\
\hline Variables & $\mathrm{b} / \mathrm{m}$ & $\mathrm{L}_{1} / \mathrm{m}$ & $\mathrm{L}_{2} / \mathrm{m}$ \\
\hline Value & 0.27 & 0.011 & 0.016 \\
\hline
\end{tabular}

Figure 4 shows the PIV measurement area. As shown in Fig.4, the measurement area is fan-shaped. The inner radius (R1) is $180 \mathrm{~mm}$ and the outer radius (R2) is $260 \mathrm{~mm}$. The circumference angle is 26 degrees, bisected by the plumb line. The plumb angle is set to 0 degrees. The clockwise rotation direction of the plumb line is negative, and the counter clockwise rotation direction is positive. Three circumferential positions are selected for data analysis. The circumferential angles are 0 degrees, 2 degrees and 4 degrees respectively. 


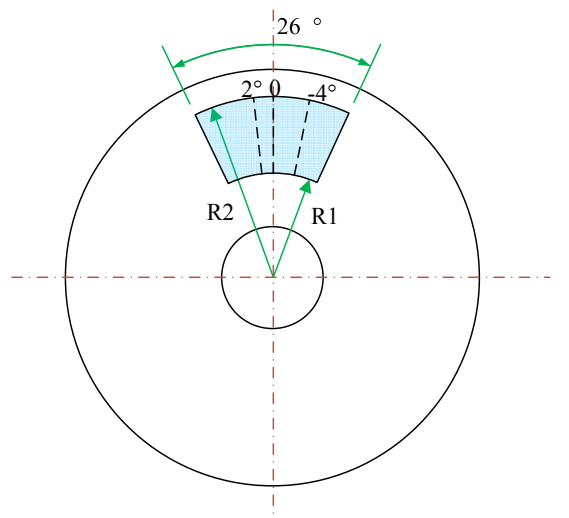

Fig. 4. Schematic diagram of PIV measurement area.

\subsection{Experimental procedure}

The test conditions are shown in Table 2. The flow fields are measured in the condition of different rotational Reynolds numbers (denoted as $\mathrm{Re}_{\varphi}$ ) and nondimensional mass flow rates (denoted as $\mathrm{Cw}$ ). The variation range of rotational Reynolds number is 1190667-2381301, and the range of dimensionless mass flow is $2535-3680$.

\section{Table 2 Operating conditions}

\begin{tabular}{|l|l|}
\hline Outlet static pressure $P_{\text {sout }}(\mathrm{KPa})$ & 128 \\
\hline Inlet total temperature $\mathrm{T}_{\text {in }}{ }^{*}(\mathrm{~K})$ & 310 \\
\hline \multirow{2}{*}{ Nondimensional mass flow rate $C_{W}$} & $2535-$ \\
& 3680 \\
\hline \multirow{2}{*}{ Rotational Reynolds numbers $\operatorname{Re}_{\varphi}$} & $1190667-$ \\
& 2381301 \\
\hline
\end{tabular}

The rotational Reynolds number is defined as

$\operatorname{Re}_{\varphi}=\frac{\rho \omega b^{2}}{\mu}$

where $\rho$ is the density calculated from the following Eq. (2) (Anderson 2010) and $\omega$ is the rotational speed of the rotor. $b$ is the outer radius of rotor. $\mu$ is dynamic viscosity of the air.

$\rho=\frac{P}{R T}$

where $\mathrm{P}$ and $\mathrm{T}$ are static pressure and static temperature of the air, respectively. $\mathrm{R}$ is universal gas constant.

The nondimensional mass flow rate is defined as

$C_{\text {WI }}=\frac{m}{\mu b}$

where $\mathrm{m}$ is the inlet mass flow rate, $\mathrm{b}$ and $\mu$ are the same as defined in Eq. (1).

The swirl ratio is defined as
$\beta=\frac{V_{\phi}}{\omega r}$

where $V_{\varphi}$ is the tangential velocity of airflow in the rotor-stator cavity, $r$ is the local radial height.

\subsection{Uncertainty analysis}

Beyond the geometry concerns, the error of rotational Reynolds number according to Eq. (1) is from the error of $\omega$. The error of nondimensional mass flow rate according to Eq. (3) is from the error of $\mathrm{m}$.

Experimental uncertainty estimates are determined using the single-sample approaches described by Kline and McClintock (1953). With this approach, the uncertainty of measurement can be calculated from

$$
\begin{aligned}
& \frac{\Delta \operatorname{Re}}{\operatorname{Re}}=\frac{\Delta \omega}{\omega} \\
& \frac{\Delta C_{W}}{C_{W}}=\frac{\Delta m}{m}
\end{aligned}
$$

Through computation with the equations above, the maximum uncertainty of Reynolds number is $0.04 \%$. The maximum uncertainties of nondimensional mass flow rate is $1.5 \%$.

The required accuracy in PIV measurements is only possible by rigorous developments. The main sources of uncertainty associated with the PIV measurements are well known, (Raffel et al. 2007), quantifying their corresponding uncertainty bounds continuously to be challenged. Uncertainties can be caused by hardware/experimental setup and algorithm selection. Each of these sources of error can manifest itself as a random or systematic error. There are many studies that have investigated the uncertainty quantification for PIV measurements, (Iliescu et al. 2008). The factors affecting the measurements accuracy were investigated and their impact on the result was estimated. The range of uncertainty of the velocity measurements was normally estimated to be $2-3 \%$ of the measured value, (Rahul et al. 2018).

\section{RESULT AND DISCUSSION}

\subsection{Flow characteristics in the rotor-stator cavity}

Figure 5 presents the nondimensional velocity distribution of the planes at different axial locations. The locations of $L_{1}{ }^{*}$ and $L_{2}{ }^{*}$ have already been illustrated in Fig. 3. The rotational Reynolds number of the rotor is $1.49 \times 10^{6}$ and the nondimensional mass flow rate of the inlet is 3680 . It can be seen from the velocity vector in Fig. 5 that the airflow in the rotorstator cavity mainly moves in the circumferential direction. This means that although the flow in the rotor-stator cavity is very complicated, the flow in the rotor-stator cavity is still dominated by circumferential motion. Compared with the circumferential velocity, the radial velocity is quite small. At the same radial position, the velocity is basically unchanged along the circumference. At the same circumferential position, the velocity increases 
with the increase of radial position which is mainly due to the higher circumferential velocity at the high radius position. Both $L_{1}{ }^{*}$ and $L_{2}{ }^{*}$ are located in the core region. But compared with $L_{2}{ }^{*}$, the velocity at

the low radius region in the $L_{1}{ }^{*}$ plane is smaller than that in the $L_{2}{ }^{*}$ plane. However, the velocity at the high radius region in the $L_{1}{ }^{*}$ plane is larger than that in the $L_{2}{ }^{*}$ plane. That means the velocity distribution is different in different axial positions. In addition, the velocity on the $L_{1}{ }^{*}$ plane which is closer to the rotor varies more along the radial direction, as will be shown later in this manuscript.

Figure 6 shows the nondimensional circumferential velocity distribution of the planes at different axial positions. The legend in Fig.6 is the same as Fig.5. It can be seen that the color distribution in Fig. 6 is similar to that in Fig.5 in the same axial position. This means that the flow in the core region of the rotor-stator cavity is mainly circumferential flow, and the proportion of radial flow is very small. In the location of $L_{1}{ }^{*}$, the circumferential velocity increases along the radial direction which is the same in the location of $L_{2}{ }^{*}$. The minimum and maximum nondimensional circumferential velocity are 0.102 and 0.213 , respectively. The speed increment is $109 \%$. In the location of $L_{2}{ }^{*}$, however, the minimum and maximum nondimensional circumferential velocity are 0.138 and 0.207 , respectively. The speed increment is $50 \%$, which is lower than that at $L_{1}{ }^{*}$.

This means that the closer to the rotor, the more uneven the flow in the rotor-stator cavity is. It can also be seen from the figure that the circumferential velocity in the lower radius position at $L_{1}{ }^{*}$ plane is smaller than that at $L_{2}{ }^{*}$ plane. However, in the higher radius position, the circumferential velocity at $L_{1}{ }^{*}$ plane is larger than that at $L_{2}{ }^{*}$ plane. This shows that the contribution of rotor motion to the circumferential velocity of the fluid near the rotor is small in the low radius region, but large in the high radius region. The results show that the disturbance of the rotor rotating motion to the fluid in the rotorstator cavity mainly occurs in the high radius region. The high radius region should be paid more attention to in the process of reforming the flow field characteristics in the rotor-stator cavity.

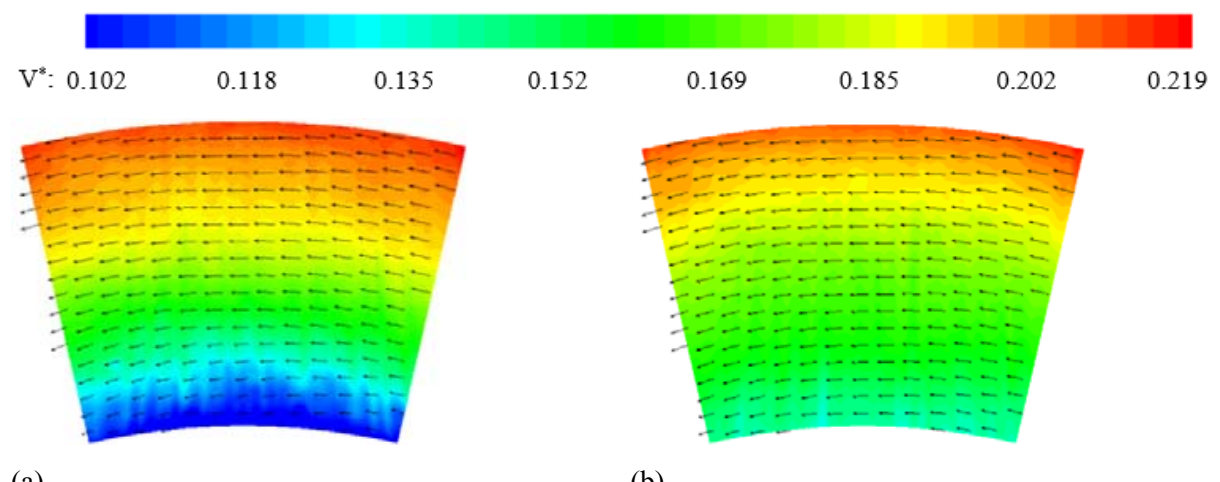

(a)

(b)

Fig. 5. Velocity distribution of the planes at different axial position: (a) $L_{1}{ }^{*}=0.04$ and (b) $L_{2}{ }^{*}=0.06$.

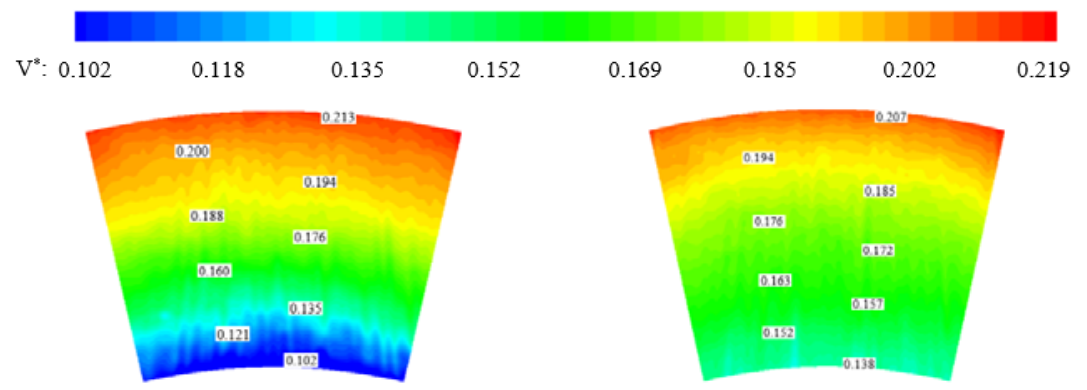

(a)

(b)

Fig. 6. Circumferential velocity distribution of the planes at different axial position: (a) $L_{1}{ }^{*}=0.04$ and (b) $\mathbf{L}_{2}{ }^{*}=\mathbf{0 . 0 6}$.

Figure 7 shows the radial distribution of swirl ratio at different axial positions. The swirl ratio represents the acceleration effect of the rotor on the fluid in the rotor-stator cavity. In Fig.7, in the location of $L_{1}{ }^{*}$, the swirl ratio first increases and then remains unchanged with the increase of $\mathrm{r} / \mathrm{b}$. However, in the location of $L_{2}{ }^{*}$, the swirl ratio decreases slightly with the increase of $\mathrm{r} / \mathrm{b}$. This shows that the rotational 
motion of the rotor has a significant effect on the circumferential acceleration of the fluid near the rotor in the range of $0.65<\mathrm{r} / \mathrm{b}<0.85$. In Fig.7(a), the swirl ratio increases by $17.1 \%$. When $\mathrm{CW}_{\mathrm{W}}$ increases to 3680 , as shown in Fig.7(b), the swirl ratio increases by $40.9 \%$ which is much higher than that in Fig.7(a). This shows that the larger the $\mathrm{C}_{\mathrm{W}}$, the more obvious the acceleration effect of the rotor on the fluid is. This is because the increase of nondimensional mass flow rate leads to a small swirl ratio at $r / b=0.67$. With the increase of $r / b$, due to the work done by the rotor to the fluid, the swirl ratio increases significantly, and then remains unchanged at the value of 0.17 . When $R_{\varphi}$ increases to $1.49 \times 10^{6}$, the variation of swirl ratio along the radial direction is basically consistent with that in Fig.7(b). It appears that the effect of $\operatorname{Re}_{\varphi}$ on the radial distribution of swirl ratio is small in the range of $1.19 \times 10^{6}<\operatorname{Re}_{\varphi}<1.49 \times 10^{6}$. This may be due to that the change of $\operatorname{Re}_{\varphi}$ is too small. In addition, it can be seen from Fig. 7 that the radial average value of swirl ratio at $L_{2}{ }^{*}$ is slightly lower than the stable value at the high radius at $L_{1}{ }^{*}$. It is speculated that this may be due to the backflow of high radius fluid at $L_{1}{ }^{*}$ to the core region at $L_{2}{ }^{*}$. Due to the friction resistance of the stator wall, the swirl ratio of the backflow is slightly reduced.

Figure 8 shows the radial distribution of swirl ratio at different circumferential positions. The test conditions are $\mathrm{Re}_{\varphi}=1.19 \times 10^{6}$ and $\mathrm{C}_{\mathrm{W}}=2535$. The three circumferential positions have been shown in Fig.4. As shown in Fig.8, the swirl ratio fluctuates and increases along the radius increasing direction. In the range of $0.65<\mathrm{r} / \mathrm{b}<0.75$, the distributions of swirl ratio are different in different circumferential positions. When $r / b>0.75$, the variation of swirl ratio in different circumferential positions is almost the same along the radial direction. At the three circumferential positions, 0 degrees, 2 degrees and 4 degrees, the average values of swirl ratio along the radial direction are $0.1875,0.1869$ and 0.1873 , respectively. The relative deviation between the maximum value and the minimum value is only $0.3 \%$. It appears that in the low radius region, the swirl ratio is different along the circumference. However, in the high radius region, the swirl ratio is basically uniform along the circumference.

\subsection{Effect of $\operatorname{Re}_{\varphi}$}

Figure 9 shows the nondimensional velocity distribution of the planes at different rotational Reynolds numbers $\left(\operatorname{Re}_{\varphi}\right)$. The range of rotational Reynolds number of the rotor is $1.79 \times 10^{6}<\operatorname{Re}_{\varphi}<2.38 \times 10^{6}$ and the nondimensional mass flow rate $\left(\mathrm{C}_{\mathrm{W}}\right)$ of the inlet is 2535 . With the increase of $\operatorname{Re}_{\varphi}$, the absolute velocity increases, regardless of low radius or high radius. At the same $\operatorname{Re}_{\varphi}$, the velocity is basically unchanged along the circumference.

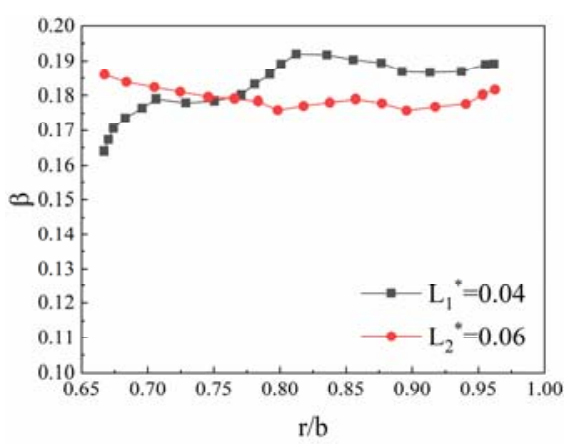

(a)

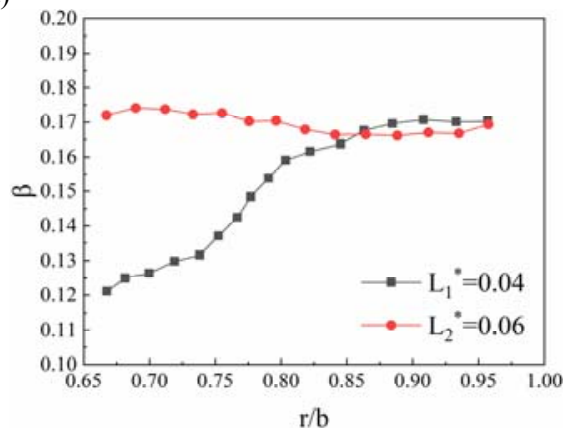

(b)

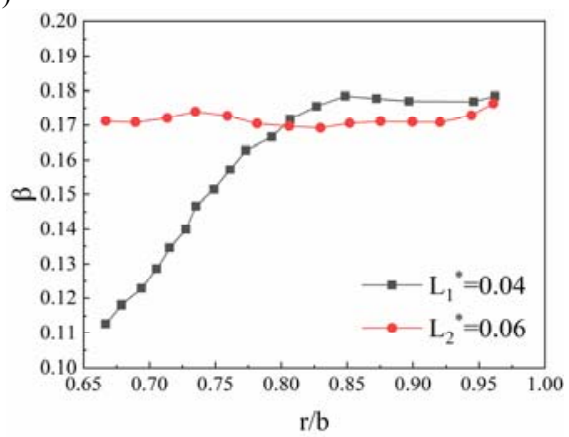

(c)

Fig. 7. Radial distribution of swirl ratio at different axial positions: (a) $\operatorname{Re}_{\varphi}=1.19 \times 10^{6}$, $C_{w}=2535$, (b) $R_{e}=1.19 \times 10^{6}, C_{w}=3680$ and (c) $\operatorname{Re}_{\varphi}=1.49 \times 10^{6}, C_{w}=3680$.

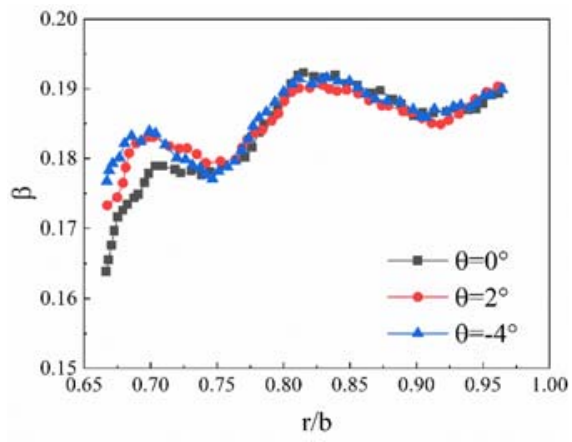

Fig. 8. Radial distribution of swirl ratio at different circumferential positions. 


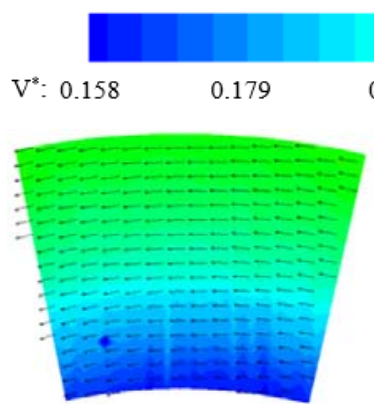

(a)

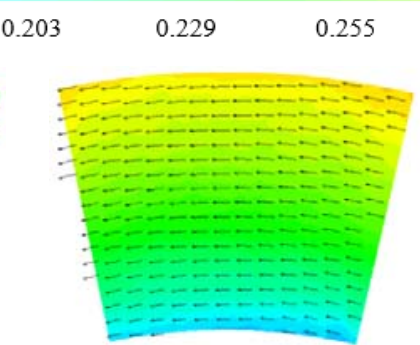

(b)
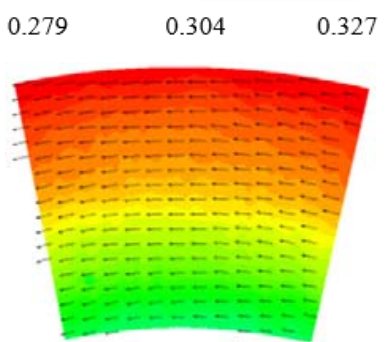

(c)

Fig. 9. Velocity distribution of the planes at different $\operatorname{Re}_{\varphi}: \operatorname{Re}_{\varphi}=1.79 \times 10^{6}$, (b) $\operatorname{Re}_{\varphi}=2.08 \times 10^{6}$ and (c) $\operatorname{Re}_{\varphi}=2.38 \times 10^{6}$.

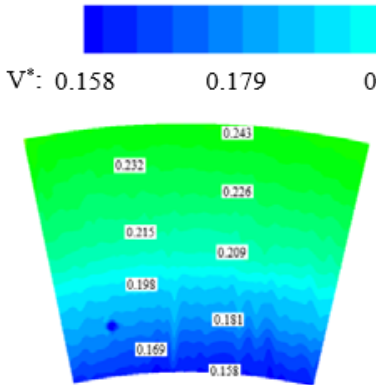

(a) (b)

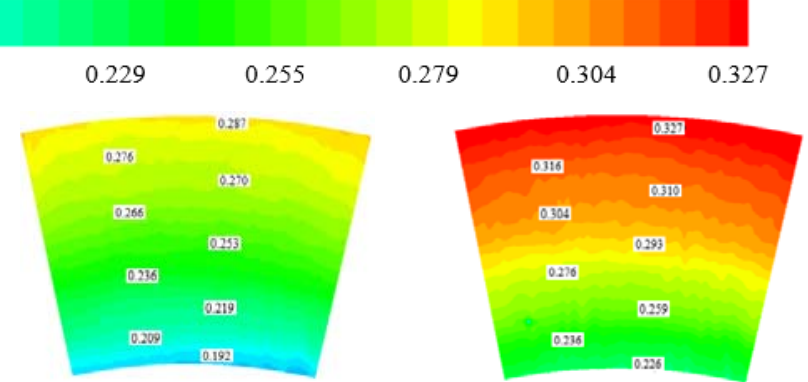

(c)

Fig. 10. Circumferential velocity distribution of the planes at different $\operatorname{Re}_{\varphi}: \operatorname{Re}_{\varphi}=1.79 \times 10^{6}$, (b) $\operatorname{Re}_{\varphi}=2.08 \times 10^{6}$ and (c) $\operatorname{Re}_{\varphi}=2.38 \times 10^{6}$.

Figure 10 shows the nondimensional circumferential velocity distribution of the planes at different rotational Reynolds numbers $\left(\operatorname{Re}_{\varphi}\right)$. At the low radius position, the minimum value of circumferential velocity increases from 0.158 to 0.226 as the $\operatorname{Re}_{\varphi}$ increases from $1.79 \times 10^{6}$ to $2.38 \times 10^{6}$. The circumferential velocity increased by $43 \%$. At the high radius position, the maximum value of circumferential velocity increases from 0.243 to 0.327 as the $\operatorname{Re}_{\varphi}$ increases from $1.79 \times 10^{6}$ to $2.38 \times 10^{6}$. The circumferential velocity increased by $35 \%$. This shows that the increase of $\operatorname{Re}_{\varphi}$ makes the

circumferential acceleration of low radius fluid more obvious. When $\operatorname{Re}_{\varphi}=1.79 \times 10^{6}$, the circumferential velocity increases with the increase of radius. The circumferential velocity increment is $53.8 \%$. When $\mathrm{Re}_{\varphi}=2.38 \times 10^{6}$, the circumferential velocity increment is $45.2 \%$. This shows that the increment of circumferential velocity along the radial direction decreases with the increase of rotational Reynolds number. Higher rotational Reynolds number will reduce the radial distribution difference of circumferential velocity.

Figure 11(a) shows the radial distribution of swirl ratio at different rotational Reynolds numbers. The range of rotational Reynolds number of the rotor is $1.19 \times 10^{6}<\operatorname{Re}_{\varphi}<2.38 \times 10^{6}$ and the nondimensional mass flow rate $\left(\mathrm{C}_{\mathrm{W}}\right)$ of the inlet is 2535 . As shown in Fig.11(a), the swirl ratio increases with the increase of rotational Reynolds number. The swirl ratio fluctuates and increases along the radius increasing direction in the range of $0.65<\mathrm{r} / \mathrm{b}<0.81$. With the increase of rotational Reynolds number, the fluctuation decreases gradually. When $r / b>0.81$, the swirl ratio fluctuates less along the radial direction and tends to a stable value. When $\operatorname{Re}_{\varphi}=1.19 \times 10^{6}$, the relative deviation between the maximum value and the minimum value of the swirl ratio is $17.1 \%$. When the rotational Reynolds number increases to $2.38 \times 10^{6}$, the relative deviation between the maximum value and the minimum value of the swirl ratio decreases by $6.6 \%$. This indicates that a higher rotational Reynolds number will reduce the radial difference of the swirl ratio, which is consistent with the conclusion in Fig.10

Figure 11(b) compares the current results with the experimental results in the literature Tao et al. (2007). As shown in Fig.11 (b), the radial distribution of swirl ratio is contrary to the law in the literature Tao et al. (2007). This is because the experimental model in the literature adopts a high radius air inlet, which is contrary to the current research model. However, there are still common rules to compare. At the same mass flow rate, the swirl ratio of the core flow increases with the increase of the rotational Reynolds number. The 


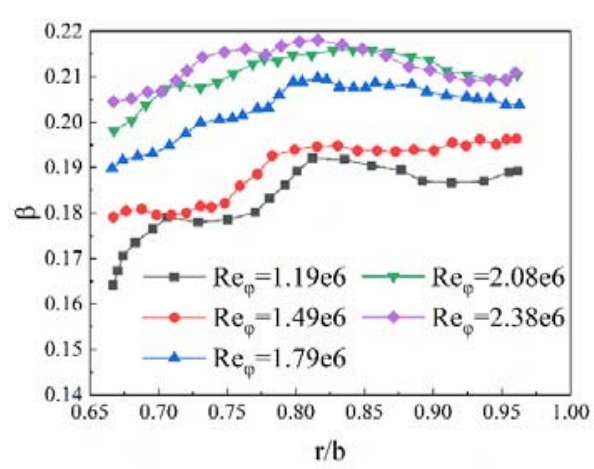

(a)

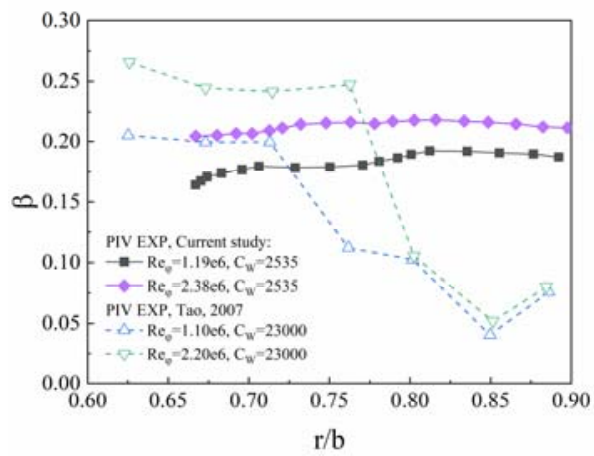

(b)

Fig. 11. Radial distribution of swirl ratio at different $\operatorname{Re}_{\varphi}$.

measured swirl ratio in the core region is lower than the theoretical value of 0.43 in the enclosed rotorstator cavity. Compared with the literature, the swirl ratio of the current study fluctuates less along the radial direction, which is due to the smaller nondimensional mass flow rate $(\mathrm{Cw})$ of the current study. This indicates that the smaller the $\mathrm{Cw}_{\mathrm{w}}$, the more uniform the radial flow in the core region is

\subsection{Effect of $\mathrm{C}_{\mathrm{w}}$}

Figure 12 shows the nondimensional velocity distribution of the planes at different nondimensional mass flow rates $\left(\mathrm{C}_{\mathrm{W}}\right)$. The range of nondimensional mass flow rate of the inlet is $2535<\mathrm{CW}<3680$ and the rotational Reynolds number of the rotor is $1.19 \times 10^{6}$. With the increase of $\mathrm{C}_{\mathrm{W}}$, the absolute velocity decreases, regardless of the low radius or high radius. The reason is that when the nondimensional mass flow rate increases, the rotational Reynolds number remains unchanged and the input work of the rotor to the fluid remains unchanged. However, as the nondimensional mass flow rate in the rotor-stator cavity increases, the energy received by the fluid per unit mass decreases, resulting in the decrease of the absolute velocity. At the same $\mathrm{CW}$, the velocity is basically unchanged along the circumference.

Figure 13 shows the nondimensional circumferential velocity distribution of the planes at different nondimensional mass flow rates $(\mathrm{CW})$. With the increase of $\mathrm{C}_{\mathrm{W}}$, the circumferential velocity decreases, regardless of low radius or high radius. At the low radius position, the minimum value of circumferential velocity decreases from 0.153 to 0.146 as the $\mathrm{CW}_{\mathrm{W}}$ increases from 2535 to 3680 . The circumferential velocity decreased by $4.8 \%$. At the high radius position, the maximum value of circumferential velocity decreases from 0.212 to 0.201 as the $\mathrm{CW}_{\mathrm{W}}$ increases from 2535 to 3680 . The circumferential velocity decreased by $5.5 \%$. This shows that the increase of $\mathrm{C}_{\mathrm{W}}$ makes the decrease of circumferential velocity of low radius fluid more obvious. When $\mathrm{C}_{\mathrm{W}}=2535$, the circumferential velocity increases with the increase of radius. The circumferential velocity increment is $38.1 \%$. When $\mathrm{C}_{\mathrm{W}}=3680$, the circumferential velocity increment is $37.5 \%$. This shows that the increment of circumferential velocity along the radial direction decreases with the increase of $\mathrm{C}_{\mathrm{W}}$. Higher nondimensional mass flow rate will reduce the radial distribution difference of circumferential velocity.

Figure 14 shows the radial distribution of swirl ratio at different nondimensional mass flow rates. The range of nondimensional mass flow rate of the inlet is $2535<\mathrm{CW}_{\mathrm{W}}<3680$ and the rotational Reynolds number of the rotor is $1.19 \times 10^{6}$. As shown in Fig.14, the swirl ratio decreases with the increase of

nondimensional mass flow rate. The swirl ratio fluctuates and increases along the radius increasing direction in the range of $0.65<\mathrm{r} / \mathrm{b}<0.81$. With the increase of nondimensional mass flow rate, the fluctuation decreases. When $r / b>0.81$, the swirl ratio fluctuates less along the radial direction and tends to a stable value. When $\mathrm{C}_{\mathrm{W}}=2535$, the relative deviation between the maximum value and the minimum value

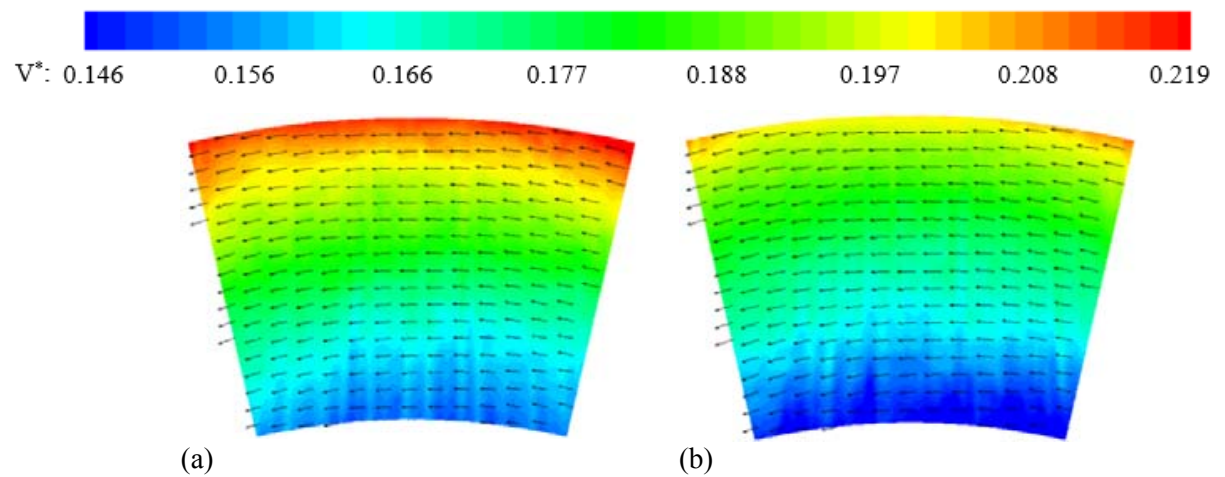

Fig. 12. Velocity distribution of the planes at different $\mathrm{Cw}_{w}$ : (a) $\mathrm{C}_{w}=2535$ and (b) $\mathrm{C}_{w}=\mathbf{3 6 8 0}$. 


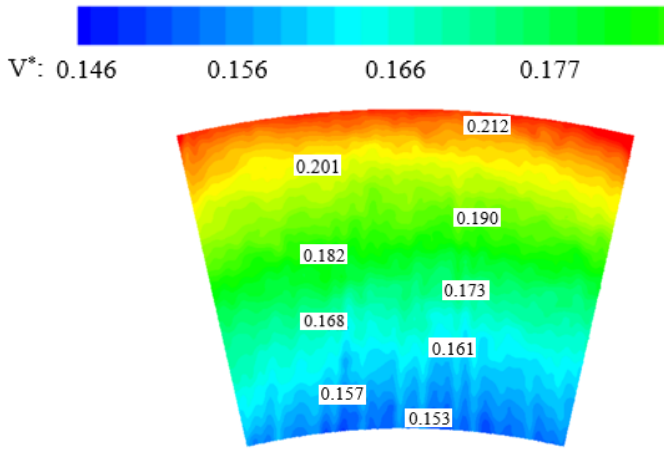

(a)

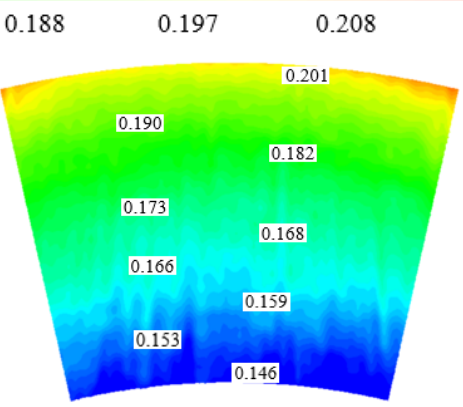

(b)

Fig. 13. Circumferential velocity distribution of the planes at different $\mathrm{Cw}_{\mathrm{w}}$ : (a) $\mathrm{CW}_{\mathrm{w}}=2535$ and (b) $\mathrm{C}_{\mathrm{w}}=\mathbf{3 6 8 0}$.

of the swirl ratio is $17.6 \%$. When $\mathrm{CW}_{\mathrm{W}}=3680$, the relative deviation between the maximum value and the minimum value of the swirl ratio increases by $41.5 \%$. This indicates that a higher nondimensional mass flow rate will increase the radial difference of swirl ratio.

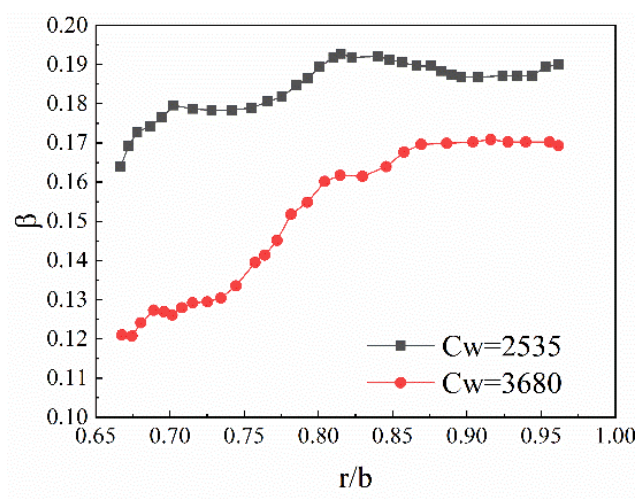

Fig. 14. Radial distribution of swirl ratio at different $\mathrm{C}_{\mathrm{w}}$.

\section{Conclusions}

The fluid flow characteristics in a rotor-stator cavity with inlet at low radius are investigated experimentally in this manuscript. The major conclusions through the present work can be summarized as follows:

1. The velocity distributions in the rotor-stator cavity are measured by PIV technique. The detailed distributions provide a better understanding of the flow field in a rotor-stator cavity. The velocity distributions at different axial locations, rotational Reynolds numbers (denoted as $\operatorname{Re}_{\varphi}$ ) and nondimensional mass flow rates (denoted as $\mathrm{C}_{W}$ ) are investigated respectively.

2. It is clear that although the flow in the rotor-stator cavity is very complicated, the flow in the rotorstator cavity is still dominated by circumferential motion. For low radius intake, the velocity increases with the increase of radial position. The velocity distribution is different in different axial positions.
The closer to the rotor, the more uneven the flow in the rotor-stator cavity is. The disturbance of the rotor rotating motion to the fluid in the rotor-stator cavity mainly occurs in the high radius region. It can be expected that the high radius region should be paid more attention to in the process of reforming the flow field characteristics in the rotor-stator cavity.

3. The increase of $\operatorname{Re}_{\varphi}$ will improve the uniformity of flow field in the rotor-stator cavity. The increase of $\operatorname{Re}_{\varphi}$ makes the circumferential acceleration of low radius fluid more obvious. Higher rotational Reynolds number will reduce the radial distribution difference of circumferential velocity. The swirl ratio increases with the increase of rotational Reynolds number.

4. The increase of $\mathrm{CW}_{\mathrm{W}}$ makes the decrease of circumferential velocity of low radius fluid more obvious. The increment of circumferential velocity along the radial direction decreases with the increase of $\mathrm{C}_{\mathrm{W}}$. Higher nondimensional mass flow rate will reduce the radial distribution difference of circumferential velocity. The swirl ratio decreases with the increase of nondimensional mass flow rate. The swirl ratio fluctuates and increases along the radius increasing direction and tends to a stable value. Higher nondimensional mass flow rate will increase the radial difference of the swirl ratio.

\section{ACKNOWLEDGEMENTS}

The authors gratefully acknowledge the financial support from the National Science and Technology Major Project (2017-I-0005-0006) and the support of Northwestern Polytechnical University for providing some facilities to complete this research contents.

\section{REFERENCES}

Anderson, J. D. (2010). Fundamentals of aerodynamics. Tata McGraw-Hill Education.

Batchelor, G. K. (1951). Note on the class of solutions of the Navier-Stokes equations representing steady rotationally symmetric flow. The Quarterly Journal of Mechanics and Applied Mathematics 4(1), 29-41.

Bayley, F. J. and J. M. Owen (1970). The fluid 
H. L. Ren et al. / JAFM, Vol. 15, No. 1, pp. 73-84, 2022

dynamics of a shrouded disc system with a radial outflow of coolant. Journal of Engineering for Power 92, 335-341.

Childs, P. R. N. (2011). Rotating flows. Elsevier, London.

Chew, J. W. and C. M. Vaughan (1988). Numerical Predictions for the flow induced by an enclosed Rotating disk. 33rd ASME Int. Gas Turbine Conf, Amsterdam, Paper No.88-GT-127.

Coren, D., P. R. N. Childs and C. A. Long (2009). Windage sources in smooth-walled rotating disc systems. Proceedings of the Institution of Mechanical Engineers, Part C: Journal of Mechanical Engineering Science 223(4), 873888.

Chew, J. W. (1991). A theoretical study of ingress for shrouded rotating disc systems with radial outflow. Journal of Turbomachinery 113, 9197.

Chew, J. W., S. Dadkhah and A. B. Turner (1992). Rim sealing of rotor-stator wheelspaces in the absence of external flow. Journal of Turbomachinery 114, 433-438

Cheah, S. C., H. Iacodives and D. C. Jackson (1994). Experimental investigation of enclosed rotorstator disc flows. Experimental Thermal and Fluid Science 9, 445-455.

Campbell, D. (1978). Gas turbine disc sealing design. Proceedings of the AGARD Conference on Seal Technology in Gas Turbine Engines, AGARDCP-237.

Daily, J. W. and R. E. Nece (1960). Chamber dimension effects on induced flow and frictional resistance of enclosed rotating discs. Journal of Basic Engineering 82(1), 217-232.

Dijkstra, D. and G. J. F. V. Heijst (1983). The flow between two finite rotating discs enclosed by a cylinder. Journal of Fluid Mechanics 128, 123154.

Dorfman, L. A. (1961). Effect of radial flow between the rotating disc and housing on their resistance and heat transfer. Izv. Akad. Nauk.-SSSR, OTN, Mekh.i Mash 4, 26-32.

Daily, J. W., W. D. Ernst and V. V. Asbedian (1964). Enclosed rotating discs with superposed throughflow: mean steady and periodic unsteady characteristics of induced flow. Cambridge: MIT Department of Civil Engineering, Hydrodynamics Laboratory Report No. 64.

Daniels, W. A., B. V. Johnson and D. J. Graber (1992). The flow between two finite rotating discs enclosed by a cylinder. Rim seal experiments and analysis for turbine applications 114(2), 426-432.

Dadkhah, S., A. B. Turner and J. W. Chew (1992). Performance of radial clearance rim seals in upstream and downstream rotor-stator wheelspaces. Journal of Turbomachinery 114,
439-445.

Hamabe, K. and K. Ishida (1992). Rim seal experiments and analysis of a rotor-stator system with non-axisymmetric main flow. ASME Paper, 92-GT-160.

Ishida, K. and K. Hamabe (1997). Effect of main flow pressure asymmetry on seal characteristics of a gas turbine rotor-stator system. ASME Paper, 97-GT-205.

Iliescu, M. S., G. D. Ciocan and F. Avellan (2008). Analysis of the cavitating draft tube vortex in a francis turbine using particle image velocimetry measurements in two-phase flow. Journal of Fluids Enginering 130(2), 1-10.

Khilnani, V. I., L. C. Tsai and S. H. Bhavnani (1994). Mainstream ingress suppression in gas turbine disk cavities. Journal of Turbomachinery 116(2), 339-346.

Kobayashi, N., M. Matsumato and M. Shizuya (1984). An experimental investigation of a gas turbine disc cooling system. Journal of Engineering for Gas Turbines and Power 106, 136-141.

Kline, S. J. and F. McClintock (1953). Describing uncertainties in single-sample experiments. Mech. Eng 75, 3-8.

Morse, A. P. (1991). Assessment of laminarturbulent transition in closed disk geometries. Journal of Turbomachinery 113(1), 131-138.

Nece, R. E. and J. M. Daily (1960). Roughness effects on frictional resistance of enclosed rotating disks. Journal of Fluids Engineering 82(3), 553-560.

Owen, J. M. (1989). An approximate solution for the flow between a rotating and a stationary disk. Journal of Turbomachinery 111(3), 323-332.

Owen, J. M and U. P. Phadke (1980). An investigation of ingress for a simple shrouded rotating disc system with a radial outflow of coolant. American Society of Mechanical Engineers, Gas Turbine Conference and Products Show, New Orleans, La.

Picha, K. G. and E. R. G. Eckert (1958). Study of the air flow between coaxial discs rotating with arbitrary velocities in an open or closed space. Proeedings of the 3rd U.S. National Congress of Applied Mechanics, 791-798.

Phadke, U. P. and J. M. Owen (1983). An investigation of ingress for an "air-cooled" shrouded rotating disk system with radialclearance seals. Journal of Engineering for Gas Turbines and Power 105(1), 178-182.

Poncet, S., R. Schiestel and M. P. Chauve (2005). Centrifugal flow in a rotor-stator cavity. Journal of Fluids Engineering 127, 687-694.

Poncet,S., M. P. Chauve and R. Schiestel (2005). Batchelor versus Stewartson flow structures in a rotor-stator cavity with throughflow. Physics 
H. L. Ren et al. / JAFM, Vol. 15, No. 1, pp. 73-84, 2022

of Fluids 17(7), 253-668.

Poncet, S. and R. Schiestel (2007). Numerical modeling of heat transfer and fluid flow in rotor-stator cavities with throughflow. International Journal of Heat and Mass Transfer 50(7), 1528-1544.

Reichert, A. W. and D. Lieser (1999). Efficiency of air-purged rotor-stator seals in combustion turbine engines. ASME Paper, 99-GT-250.

Roy, R. P., G. Xu and J. Feng (2001). A study of convective heat transfer in a model rotor-stator disk cavity. Journal of Turbomachinery 123(3), 621-632.

Raffel, M., C. E. Willert and S. Wereley (2007). Particle image velocimetry-a practical guide. ISBN 978-3-540-72308-0.

Rahul, G., B. K. Gandhi and J. C. Michel (2018). PIV measurements in francis turbine-a review and application to transient operations. Renewable and Sustainable Energy Reviews 81, 2976-2991.

Stewartson, K. (1953). On the flow between two rotating coaxial discs. Proceedings Cambridge
Philosophical Society 49(2), 333-341.

Schouveiler, L., G. P. Le and M. P. Chuave (2001). Instabilities of the flow between a rotating and a stationary disc. Journal of Fluid Mechanics 443, 329-350.

Soo, S. L. and N. J. Princeton (1958). Laminar flow over an enclosed rotating disk. Trans. ASME 80(2), 287-296.

Tao, Z., J. Gao., Y. Cai and H. T. Ding (2007). Experimental investigation of the flow field between a rotating and a stationary disk at high positioned air inflow. Journal of Aerospace Power 22 (3), 347-351 (in Chinese).

Vaughan, C. M. (1987). A numerical investigation into the effect of an external flow field on the sealing of a rotor-stator cavity. Brighton: University of Sussex.

Wu, H., H. P. Liu and G. Q. Xu (2007). Numerical study on flow field between rotating and stationary disks with high-positioned air inflow. Gas turbine experiment and research 20(2), 1317 (in Chinese). 